\title{
Sistemas educacionais do Brasil, Chile e México: análise dos currículos prescristos de Matemática
}

\author{
Dermeval Santos Cerqueria ${ }^{1}$ \\ Marcelo Navarro da Silva ${ }^{2}$
}

\begin{abstract}
RESUMO
Este artigo insere-se no contexto dos estudos comparativos sobre organização e desenvolvimento curricular, na área de Educação Matemática, no Brasil, Chile e México. A intenção é evidenciar os impactos dos resultados de pesquisa em Educação Matemática nos documentos oficiais desses países, elaborados a partir dos anos 90 do século XX e apresentar semelhanças e diferenças dos Currículos Prescritos de Matemática. Utilizou-se como percurso da comparação curricular a Educação Comparada de documentos que prescrevem os sistemas educacionais e os Currículos de Matemática da educação básica. Na análise comparativa aponta-se uma diferenciação na estruturação curricular, ênfase da álgebra no currículo chileno e mexicano e semelhança como o uso da resolução de problema no processo de ensino e aprendizagem nos três países.
\end{abstract}

PALAVRAS-CHAVE: Brasil. Chile. Currículos de Matemática. Educação Comparada. México.

Educational systems in Brazil, Chile and Mexico: analysis of prescribed mathematics curriculum

\section{ABSTRACT}

This article is part of the comparative studies on organization and

\footnotetext{
${ }^{1}$ Doutor em Educação Matemática. Centro Universitário das Faculdades Metropolitanas Unidas (FMU), São Paulo. https://orcid.org/0000-0003-0463-3836.dscerqueirasp@yahoo.com.br.

2 Doutor Educação Matemática. Centro Universitário das Faculdades Metropolitanas Unidas (FMU). https://orcid.org/0000-0001-9039-8937. marcelnava@yahoo.com.br.
} 
curriculum development, in the area of Mathematical Education, in Brazil, Chile and Mexico. The intention is to highlight the impacts of the research results in Mathematics Education in the official documents of these countries, elaborated from the 90 s of the 20th century and present similarities and differences of the Prescribed Mathematics Curricula. It was used as a path from the curricular comparison to the Comparative Education of documents that prescribe the educational systems and the Mathematics Curricula of basic education. The comparative analysis points out a differentiation in the curricular structure, an emphasis on algebra in the Chilean and Mexican curriculum and similarity as the use of problem solving in the teaching and learning process in the three countries.

KEYWORDS: Brazil. Chile. Mathematics Curriculum. Comparative Education. Mexico

\section{Introdução}

Iniciamos nossos estudos comparativos, em 2009, baseados nos objetivos do Projeto "Pesquisas comparativas sobre organização e desenvolvimento curricular, na área de Educação Matemática em países da América Latina” coordenado pela Professora Doutora Célia Maria Carolino Pires na PUC-SP que eram: a) Identificar aspectos comuns e especificidades dos currículos prescritos de Matemática implementados em cada um desses países, assim como as formas de organização; b) Identificar semelhanças e diferenças entre materiais didáticos utilizados nesses países, pensados como currículos apresentados; c) Buscar dados referentes aos currículos moldados pelos professores, que se aproximam do que é realizado nas salas de aula; d) Identificar fontes que evidenciem a adesão ou a rejeição dos professores de Matemática às orientações curriculares prescritas nos documentos oficiais.

Constatamos que, o intercâmbio entre pesquisadores em Educação Matemática de países ibero-americanos existe, sendo uma de suas marcas a 
criação da Federação Iberoamericana de Sociedades de Educação Matemática - FISEM, criada em 2003, e que congrega diversas sociedades como por exemplo: Sociedade Brasileira de Educação Matemática (SBEM), Sociedad Chilena de Educación Matemática (SOCHIEM), Associação Nacional de Professores de Matemática (ANPM) e Associação Mexicana de Investigadores do Uso de Tecnologia em Educação Matemática (AMIUTEM), ambas, respectivamente, no México.

Tais intercâmbios permitem formularmos conceitos e teorizações de estudos sobre Educação Matemática, fazendo com que produzam impactos nas políticas públicas, especialmente nas políticas curriculares desses países esse objeto de investigação não coube a essa pesquisa.

Para realizar um estudo comparado, fundamentamos em Ferrer (2002), citando sua afirmação de que a Educação Comparada permite destacar quatro finalidades:

I) Ilustrar as diferenças ou semelhanças entre os sistemas educativos de vários países; II) Mostrar a importância que têm os fatores contextuais dos sistemas educativos como elementos explicativos de si mesmo; III) Estabelecer as possiveis influências que têm os sistemas educativos sobre determinados fatores contextuais; IV) Contribuir para compreender melhor o nosso sistema educativo mediante o conhecimento do sistema educativos de outros países (FERRER, 2002, p.23).

O autor defende ainda que a Educação Comparada tem uma ampla tradição desde o inicio do século XIX, e que para abordar esse tema é necessário estruturar a pesquisa em seis fases básicas que são fase pré descritiva, fase descritiva, fase interpretativa, fase de justaposição, fase comparativa, fase prospectiva.

Assim, Ferrer (2002), considera que essas fases são características dos estudos de Educação Comparada, realizados ao longo da História e que se desenvolvem com exatidão. Também afirma ser uma classificação rigorosa do 
ponto de vista cientifico e metodologicamente esclarecedora.

Considerando-se as fases apresentadas por Ferrer (2002), debruçamos em pesquisas nas diversas fontes disponíveis em sites do $\mathrm{INEP}^{3}$ (Instituto Nacional de Estudos e Pesquisas Educacionais Anísio Teixeira - Brasil), MINEDUC4 (Ministerio de Educación - Chile) e SEP5 (Secretaría de Educación Pública - México). Como justificativa para nossos estudos encontramos em Pires (2000), a afirmação de que muitos países estavam se dedicando a rever seus currículos educacionais, em especial o de Matemática, principalmente impulsionados pelo fracasso reconhecido mundialmente do Movimento da Matemática Moderna $(\mathrm{MMM})^{6}$. No período que sucedeu a Matemática Moderna, em vários países, novas propostas começaram a ser elaboradas. Nesse cenário, entende-se como relevante, a discussão sobre Currículos de Matemática prescritos no Brasil, Chile e México, dado pelos motivos que se passam na sequência.

Ao conceber um plano para a Educação, para alunos que tem idade compreendida entre seis e dezessete anos, é necessário que os elaboradores que estão à frente dessa iniciativa explicitem quais são as finalidades da Educação, suas concepções e os princípios que nortearão toda a trajetória para a concretização dos objetivos traçados.

Outro aspecto importante a considerar é a pluralidade cultural existente em diferentes regiões de um mesmo país. Essas diferentes culturas devem ser valorizadas e privilegiadas, tampouco deve ser proposto um núcleo comum de conhecimentos das diferentes disciplinas para serem ensinadas no âmbito nacional, permitindo a inserção dos conhecimentos que cada secretaria das diversas regiões entenda como importante para suas comunidades. A esse conjunto de concepções, objetivos e finalidades do ensino proposto, orientações didático-metodológicas, princípios, lista de conteúdos a

\footnotetext{
${ }^{3}$ http://www.inep.gov.br/

4 https://www.mineduc.cl/

5 https://www.gob.mx/sep

${ }_{6}^{6}$ O Movimento da Matemática Moderna (MMM) foi uma tendência pedagógica implementada nas décadas de 60 e 70 do século XX e foi marcado por uma nova abordagem que tinha como foco as estruturas algébricas e a teoria dos números.
} 
serem trabalhados em sala de aula e exemplos de atividades com encaminhamentos, entre outros, são entendidos como parte de um currículo.

Outra justificativa plausível para a nossa pesquisa é identificar se, nos Currículos de Matemática oficiais e prescritos para o ensino de Matemática do Brasil, Chile e México, há um enfoque nas orientações veiculadas pela Educação Matemática enfatizando o uso das novas tecnologias e metodologias ativas, bem como, a Contextualização e Matematização de situações problemas, o Letramento Matemático, a Literária, Modelagem Matemática a Etnomatemática, dentre outros vários temas que corroboram com a construção do conhecimento matemático.

Dessa forma, tínhamos interesse em saber que contribuições à área de Educação Matemática vêm dando e ainda tem para oferecer a esses países, pressupondo que a produção na área vem crescendo significativamente, tanto nacional, como internacionalmente.

Uma hipótese de nossa investigação consistia em reconhecer que nos últimos 20 anos as mudanças curriculares, influenciadas pelas pesquisas na área da Educação e da Educação específica de Matemática, tornaram-se relevantes em diversos países, particularmente no Brasil, Chile e México.

As análises propostas à realização por meio de leituras, observações, entrevistas e reflexões, devem conduzir à meta, que se restringe à busca e revelação de informações que permitam responder "quais são as influências da Educação Matemática nos currículos de Matemática do Brasil, Chile e México?"

A proposta desse texto se limitará aos Sistemas Educacionais e dos Currículos prescritos de Matemática do Brasil, Chile e México com enfoque nas evidências de similaridades e diferenças dos Currículos dos países comparados. Portanto, as comparações serão feitas com documentos oficiais que regem os Sistemas Educativos e que prescrevem os Currículos de Matemática da Educação Básica, embasadas na teoria sobre Currículos de Sacristán (2000). 


\section{Ideia de Currículo}

Diversos autores dedicam-se na reflexão e apresentação de uma definição para currículo. Dentre as várias proposições, elegemos a de Sacristán (2000), por considerarmos uma reflexão contemporânea e bastante pertinente.

Quando definimos o currículo estamos descrevendo a concretização das funções da própria escola e a forma particular de enfocá-la num momento histórico e social determinado, para um nível ou modalidade de educação, numa trama institucional, etc. O currículo do ensino obrigatório não tem a mesma função que o de uma especialidade universitária, ou o de uma modalidade de ensino profissional, e isso se traduz em conteúdos, formas e esquemas de racionalização interna diferentes, por que é diferente a função social de cada nível e peculiar a realidade social e pedagógica que se criou historicamente em torno dos mesmos. Como acertadamente assinala Heubner (citado por McNeil, 1983), o currículo é a forma de ter acesso ao conhecimento, não podendo esgotar seu significado em algo estático, mas através das condições em que se realiza e se converte numa forma particular de entrar em contato com a cultura. O currículo é uma práxis antes que um objeto estático emanado de um modelo coerente de pensar a educação ou as aprendizagens necessárias das crianças e dos jovens, que tampouco se esgota na parte explícita do projeto de socialização cultural nas escolas. É uma prática, expressão da função socializadora e cultural que determinada instituição tem, que reagrupa em torno dele uma série de subsistemas ou práticas diversas, entre as quais se encontra a prática pedagógica desenvolvida em instituições escolares que comumente chamamos ensino (SACRISTÁN, 2000, p. 15-16).

É notória a necessidade de destaque de algumas das preocupações que 
concernem a ideia de elaboração do currículo. Nesse caso, a definição de Sacristán (2000) não só apresenta como igualmente reforça o pensamento a respeito da questão, uma vez que a intenção principal de um currículo é de oportunizar aos estudantes acesso ao conhecimento. É importante partir da ideia sobre para quem está sendo proposto e o que se deseja alcançar. Pires (2000) afirma que ao assumir a ideia apresentada por Sacristán (2000), marca-se a diferença entre essa concepção e aquela de que currículo é simplesmente o processo centrado na definição de objetivos e conteúdos a serem trabalhados em cada etapa da escolaridade, que ainda é muito presente na tradição educacional.

Sacristán (2000) entende que o currículo para a Educação deverá considerar o processo de aprendizagem desde os primeiros anos até o último ano de escolaridade, ou seja, é um processo que leva anos enfatizando que:

(...) Desde um enfoque processual ou prático, o currículo é um objeto que se constrói no processo de configuração, implantação, concretização e expressão de determinadas práticas pedagógicas e em sua própria avaliação, como resultado das diversas intervenções que nele se operam. Seu valor real para os alunos, que aprendem seus conteúdos, depende desses processos de transformação aos quais se vê submetido (SACRISTÁN, 2000, p. 101).

Se o currículo é algo a ser construido antes e durante o processo escolar, temos que considerar que este sofrerá influência das pessoas que estão à frente das tomadas de decisões referentes ao currículo, cada uma com uma visão de ensino atrelada às suas experiências e crenças. Assim, Sacristán (2000) propõe um modelo de interpretação do currículo como algo construído no cruzamento de influências e campos de atividades diferenciados e interrelacionados.

Nessa perspectiva o autor apresenta o diagrama a seguir, relacionando a estruturação em níveis ou fases. No entanto, ratifica que esses níveis não são hierarquizados nem constituem - se de forma linear. 
FIGURA 1: A objetivação do currículo no processo de seu desenvolvimento

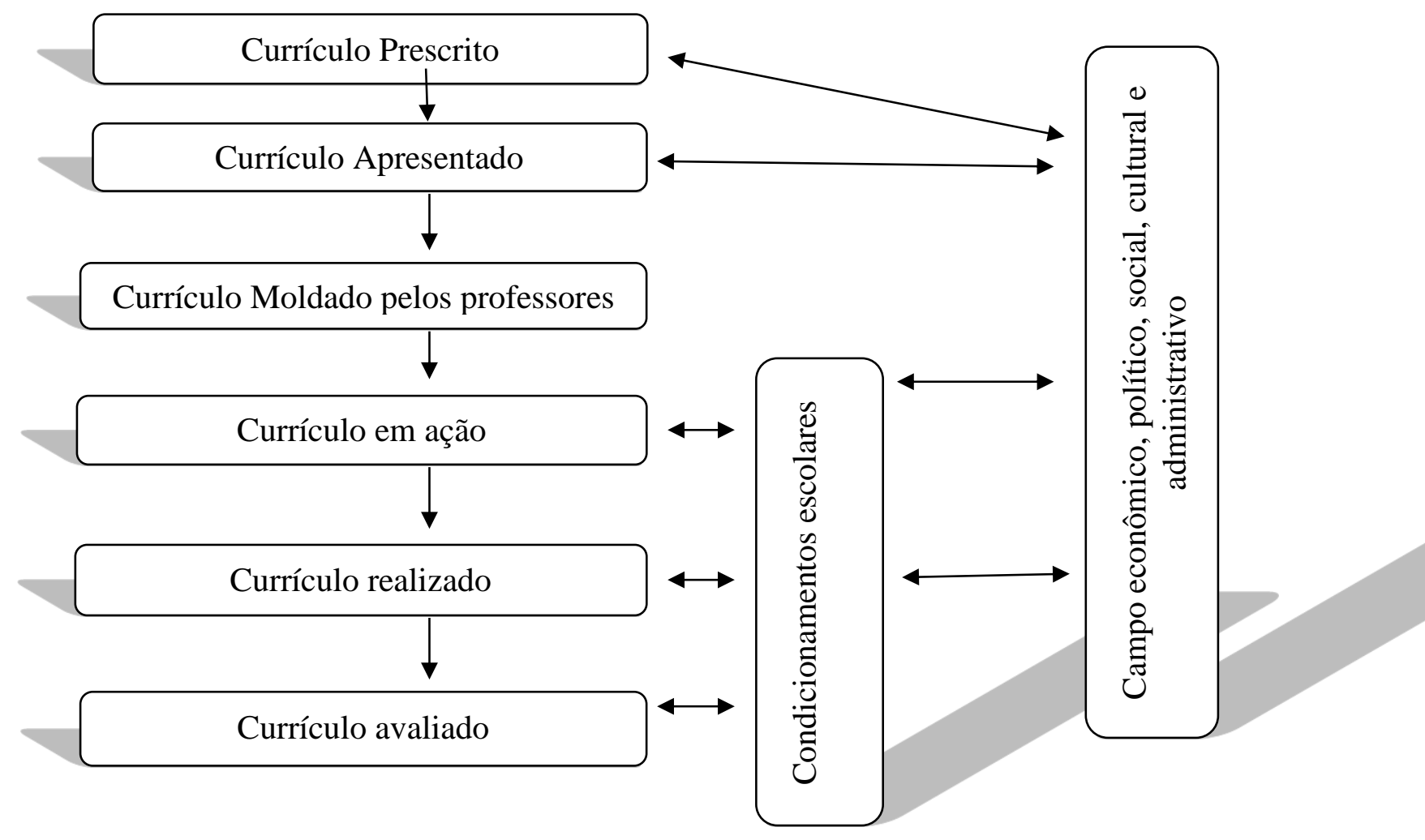

Fonte: Sacristán (2000, p. 105)

Sacristán (2000) caracteriza esses diferentes níveis, nos quais, os currículos prescritos indicam a posição da instituição governamental em termos de como ela vislumbra a educação, a escola, os processos de ensino e de aprendizagem de uma dada área de conhecimento, em face dos objetivos a serem alcançados.

Os currículos prescritos são conhecidos como currículos oficiais que determinam os conteúdos e as suas respectivas orientações de um sistema educativo. Portanto, configuram-se em documentos de referência para a elaboração de currículos apresentados.

Os currículos apresentados aos professores são em geral resultantes da formulação de autores de livros didáticos e outros materiais, que objetivam mostrar de forma traduzida as orientações curriculares expressas nos 
currículos prescritos.

Os currículos moldados pelos professores, em seu planejamento no início do ano letivo e no decorrer dele, são elaborados a partir dos currículos prescritos e apresentados e levam em conta os diagnósticos preliminares que cada professor faz sobre o que foi ensinado a esses alunos nos anos anteriores, tanto quanto o que foi aprendido. Esse plano necessariamente se desdobra em outros mais específicos, elaborados periodicamente e que inclui todas as especificidades das atividades de aprendizagem que o professor pretende realizar com seus alunos.

Os currículos em ação e os currículos efetivamente realizados, são aqueles que se concretizam em sala de aula, em que as atividades vão sendo ajustadas em função da interação entre professores, alunos e o conhecimento. Muitas vezes o que foi planejado inicialmente precisa adequar-se melhor ao grupo de alunos, seja porque são observadas dificuldades para a compreensão do que está sendo trabalhado, seja porque se observa que os alunos são capazes de realizarem atividades mais avançadas.

Para Sacristán (2000), os currículos realizados como consequência da prática, produzem efeitos complexos dos mais diversos tipos: cognitivo, afetivo, social, moral, entre outros. São efeitos aos quais, algumas vezes se presta atenção porque são considerados "rendimentos" valiosos e proeminentes do sistema ou dos métodos pedagógicos. Mas, a seu lado, se dão muitos outros efeitos, que por falta de sensibilidade para com os mesmos e por dificuldade para apreciá-los (pois muito deles, além de complexos e indefinidos, são efeitos a médio e longo prazo), ficarão como efeitos ocultos do ensino. As consequências do currículo não só se refletem em aprendizagens dos alunos, mas também afetam os professores, seja na forma de socialização profissional, ou inclusive na projeção no ambiente social, familiar, etc.

Nessa visão emerge o papel do professor reflexivo, na qual Alarcão (1996) defende a ideia de que é importante que o professor reflita sobre sua prática, com olhar aos conteúdos, como as sequências de atividades e a forma como elas se processam no contexto de ensino. 
Os currículos avaliados caracterizam-se como o momento do confronto entre as expectativas de aprendizagens que o professor se propõe a trabalhar e os resultados de aprendizagem dos alunos. O professor procura captar os avanços e dificuldades que vão se manifestando ao longo do processo, informando o que está acontecendo. Para tanto, é fundamental que ele tenha clareza quanto às expectativas de aprendizagem que devem ser buscadas, fazendo por fim um bom levantamento de conhecimentos prévios dos alunos além de realizar uma avaliação criteriosa das atividades de aprendizagem que outrora planejou e também da sua realização em sala de aula.

O nível dos currículos avaliados também pode se beneficiar das avaliações institucionais que visam a obter indicadores educacionais que possam subsidiar a elaboração de propostas de intervenção técnicopedagógica no sistema de ensino, visando a melhorar a sua qualidade e a corrigir eventuais distorções detectadas.

\section{Caminhos da comparação}

Realizamos diversas leituras de artigos científicos publicados nas diversas entidades representativas da Educação Matemática dos países pesquisados e nos congressos da área, que discorressem sobre currículos de Matemática no Brasil, Chile e México, e que ainda pudessem caracterizar o sistema educacional desses países pesquisados. Como fonte, também foram consultados documentos oficiais de ambos os países.

Na pesquisa documental, buscávamos identificar nas redes de ensino público, as ações empreendidas pelos respectivos Ministérios de Educação, no sentido de organizar currículos prescritos. Para compreender o funcionamento dos sistemas educacionais nos países pesquisados houve recorrência às pesquisas pela internet, ao acessar os sites oficiais dos Ministérios de Educação do Brasil (MEC), Ministerio de Educación del Chile (MINEDUC) e Secretaría Educación Pública del México (SEP).

$\mathrm{O}$ Brasil oferece um ambiente vasto para pesquisas relacionadas à 
Educação. Ao navegar pelo site oficial do MEC foram encontrados links que direcionam para uma busca mais refinada, tal como, a exemplo, o Instituto Nacional de Estudos e Pesquisas Educacionais - Inep 7 . Por meio do Inep foram obtidas as informações necessárias para que compreendêssemos o sistema educacional do Brasil. Como país de origem da pesquisa, o Brasil tornou obviamente possível, apresentar-se com mais familiaridade no que concernem certos aspectos da Educação, permitindo-nos ainda, um aprofundamento nas observações e análises.

Outros sites oficiais do governo brasileiro também serviram de consulta para nossa pesquisa, tal como o IBGE (Instituto Brasileiro de Geografia e Estatística) ${ }^{8}$, assim, por meio desse, foi acessado o site da Pesquisa Nacional por Amostra de Domicílios, o IBGE Instituto ${ }^{9}$. De igual forma, o Sistema de Medición de la Calidad de la Educación del Chile (SIMCE) ${ }^{10}$, também foi cientificamente vasculhado, dado a característica, que apresenta resultados de avaliações sobre conhecimentos e habilidades dos alunos da Educação Básica. Sua finalidade é de buscar elementos para nortear as ações, visando à melhoria do desempenho daquelas escolas que não tiveram um bom aproveitamento.

O Chile também mantém um acervo rico de pesquisas na área de Educação, Centro de Aperfeiçoamento, Experimentação e Investigações Pedagógicas (CEPEIP11), cujos arquivos são documentos sobre as reformas curriculares, resultados de avaliações e desempenho de alunos e das escolas por região e formação de professores. Visitamos o site e estivemos pessoalmente nessa biblioteca colhendo informações que aclaravam as dúvidas sobre os encaminhamentos propostos nos currículos e sobre as práticas dos professores frente aos documentos oficiais.

O México também dispõe de documentos para consulta pública. Os documentos que serviram para análise comparativa foram: Anuario

\footnotetext{
${ }^{7}$ www.inep.gov.br/

${ }^{8}$ www.ibge.gov.br/

${ }^{9}$ www.ibge.gov.br/home/estatistica/populacao/.../pnad2009/2010/

${ }^{10}$ Disponível: www.simce.cl

${ }^{11}$ http://www.cpeip.cl/index2.php?id_portal=41\&id_seccion=3116\&id_contenido=12364
} 
estadístico de los Estados Unidos Mexicanos ${ }^{12}$ do Instituto Nacional de Estadística y Geografia, Documento base del bachillerato general, La estrutura del sistema educativo mexicano, Panorama educativo de México e os Programas de estúdios das Matemáticas ${ }^{13}$.

O PNUD ${ }^{14}$ (Programa das Nações Unidas para o Desenvolvimento), também foi consultado. Ainda foram buscadas informações no site do Mercosul $^{15}$ e da OECD ${ }^{16}$ - Econômico, assim como na Sociedade Brasileira de Educação Matemática - SBEM17, na Sociedad Chilena de Educación Matemática o SOCHIEM18, na Asociación Mexicana de Investigadores del uso de Tecnología en Educación Matemática19.

As informações coletadas nos sites possibilitaram não só conhecer os sistemas educacionais dos três países, mas também caracterizar o Brasil, Chile e México frente aos indicadores nacionais e internacionais relacionados ao crescimento populacional, taxas de alfabetização, crescimento econômico e social, a diversidade cultural dos três países, etc.

Além de documentos oficiais pesquisados por meio de pesquisas on-line, foram encontrados diversos artigos publicados em congressos na área de Educação Matemática, ora realizados nesses países e/ou lançados em revistas especializadas na área de objeto de estudo, que por sua vez foram de grande valia para a realização das investigações.

Para o desenvolvimento da pesquisa, houve a necessidade de organização em momentos específicos, devidamente caracterizados como:

I) Aproximações com a temática. Nessa etapa o trabalho concentrou-se na busca de aportes teóricos, para que fossem realizados levantamentos de teses no portal da Capes, assim foi efetuada uma imersão, por meio de pesquisa bibliográfica nos trabalhos que pudessem trazer contribuições ao problema de

\footnotetext{
12 www.imcine.gob.mx

${ }^{13}$ www.sep.gob.mx

${ }^{14}$ www.pnud.org.br/

${ }^{15}$ www.mercosul.gov.br/

${ }^{16}$ www.oecd.org

17 www.sbem.com.br/

18 www.sochiem.cl/

${ }^{19}$ www.amiutem.edu.mx
} 
pesquisa que foi efetivamente proposto a investigar.

II) Pesquisa de documentos oficiais. Uma etapa onde procurou-se localizar documentos legais que possibilitassem a análise de currículos prescritos nos três países pesquisados para o nível de Educação Básica. Conforme dita Ludke e André (1986) que os documentos oficiais prescrevem:

[...] leis e regulamentos, normas, pareceres, cartas memorandos, diários pessoais, autobiografias, jornais, revistas, discursos, roteiros de programas de rádio e televisão até livros, estatísticas e arquivos escolares (LUDKE e ANDRÉ 1986, p.38)”.

III) Levantamento de informações sobre dados de ambos os países: nessa etapa buscou-se levantar e organizar, informações sobre dados socioeconômicos dos dois países, mas principalmente as que se referem aos sistemas educativos de cada um.

IV) Preparação para a pesquisa de campo: nessa etapa a dedicação foi voltada para entrar em contato com pessoas que pudessem contribuir para o trabalho, por meio de entrevistas, tanto no Brasil, como no Chile e no México. A meta foi de entrevistar o mesmo número de pessoas dos países em estudo, desde que houvessem experiências similares nas suas relações com os currículos de Matemática, ou seja, elaboradores, gestores e professores. Foi necessária a elaboração de roteiros de entrevistas semiestruturados, com a providência de documentos como termos de consentimento para divulgação do conteúdo das referidas entrevistas.

V) Realização da pesquisa de campo: no período de 25 a 29 de julho de 2011 foram visitadas no Chile, as cidades de Santiago, Val Paraíso e Viña Del Mar, onde foram realizadas as entrevistas com profissionais chilenos. No decorrer de 2011 e inicio de 2012, realiza-se as entrevistas com profissionais brasileiros. As entrevistas com profissionais mexicanos foram realizadas entre os dias 15 a 19 de outubro de 2014 na capital mexicana, Cidade do México, e sendo que todas as entrevistas, dos profissionais brasileiros, 
chilenos e mexicanos, foram gravadas em áudio e posteriormente transcritas. VI) Desenvolvimento da análise comparativa entre os documentos e entre as entrevistas: nessa etapa, as informações foram organizadas e coletadas.

Realizamos diversas leituras sobre currículos, que permearam elencar as categorias de análises, imprescindíveis para nossa compreensão dos dados levantados, em seus diferentes níveis de concretização, à saber: 1) O papel da Matemática na formação dos alunos brasileiros, chilenos e mexicanos; 2) Com relação à forma de estruturar o currículo prescrito; 3) Ênfase nas aplicações práticas ou nas especulações teóricas; 4) Com relação à seleção de conteúdos; 5) Com relação às orientações metodológicas e didáticas; 6) Com relação a indicações sobre o processo de avaliação da aprendizagem.

As categorias supracitadas não terão um enfoque neste artigo, como já foi mencionando em linhas anteriores, mas respostas dessas categorias sinalizam para o objetivo deste texto que é identificar semelhanças e diferenças no Sistema Educacional e nos Currículos de Matemática, e para isso, atentaremos, somente nesses dois aspectos.

\section{Evidenciando similaridades e diferenças}

Ao delimitarmos nossa investigação, nos deparamos com termos que cada país utiliza a fim de indicar a etapa educacional. No Chile, evidenciamos a Educação Básica e Média, compostas por seis anos de escolaridade cada. No México como Educação Primária e Secundária em 9 anos e Média Superior em 3 anos. No Brasil, para efeitos comparativos, temos o Ensino Fundamental, com 9 anos, e Ensino Médio, com 3 anos. Por isso, ao identificarmos os segmentos educacionais para comparação, indicávamos também a faixa etária dos alunos inseridos nessas etapas escolares. 
QUADRADO 1: Comparação dos Sistemas Educativos

Sistema Educativo da Educação Básica

\begin{tabular}{llll}
\hline Brasil & $\begin{array}{l}\text { Educação } \\
\text { Infantil }\end{array}$ & $\begin{array}{l}\text { Ensino } \\
\text { Fundamental }\end{array}$ & Ensino Médio \\
\hline Chile & Primeira & Educação Básica & Educação Média \\
& Infância & & \\
\hline México & Educação Inicial & Educação & Educação Média \\
& e Pré-escolar & $\begin{array}{l}\text { Primária } \\
\text { Secundária }\end{array}$ & \\
& & & Superior \\
& & & \\
\hline
\end{tabular}

Fonte: dos autores

Nossos estudos seriam realizado em três etapas, ao considerar, a primeira etapa compreende pesquisa bibliográfica, a segunda, pesquisa de campo, e a terceira, análises documentais e das entrevistas concedidas.

A intenção inicial resumiu-se em parear as entrevistas, ou seja, entrevistar diretores e professores de cada etapa educacional nos três países. No Brasil, colhemos alguns depoimentos de professores, diretores e formadores de professores e autores de livros que se disponibilizaram em atender-nos.

$\mathrm{Na}$ fase descritiva e interpretativa da pesquisa, houve interação com a fase da justaposição, pois, foi nesse momento, que descrevemos, interpretamos e confrontamos os dados levantados.

Dessa forma passaremos a fase comparativa, ou seja, apresentarmos quais são os impactos da Educação Matemática nos currículos de Matemática de Brasil, Chile e México. Ainda, as semelhanças e/ou diferenças evidenciadas nesses currículos, tratando o cerne da questão de nosso objeto de pesquisa.

A primeira e significativa diferença identificada é quanto ao currículo oficial prescrito. No Chile, todos os envolvidos na Educação sabem qual documento curricular que deverá usar para lecionar Matemática na Educação Básica e Média. No México os documentos que prescrevem o currículo, no caso 
os Programas de Estudos das Matemáticas, são de conhecimento dos docentes que irão atuar na disciplina de Matemática da Educação Primária, Secundária e Média Superior.

No Brasil, não há definição por parte do Ministério de Educação, de qual é o documento oficial, prescrito e aplicável, que o professor deverá apoiarse. ${ }^{20}$ Para os que atuam no Ensino Fundamental, a escolha são os Parâmetros Curriculares Nacionais, que possivelmente poderá ajudá-lo a pensar em suas aulas.

Para o Ensino Médio têm-se os Parâmetros Curriculares Nacionais para o Ensino Médio (PCNEM), (PCNEM+) e diversas Diretrizes Curriculares, as quais vem sendo anunciadas ao longo 1998 a 2010, para elucidar dúvidas e propor encaminhamentos para a concretização do ensino da Matemática nessa etapa de escolaridade.

No Ensino Fundamental e Médio do Brasil, Educação Básica e Média do Chile, Educação Primária, Secundária e Média Superior do México observamos que a estrutura curricular difere em números de blocos de conteúdo, no entanto, essa diferença é apenas escolha de cada país na forma de organização e distribuição dos conteúdos a serem desenvolvidos no decorrer dessas etapas educacionais. Verificamos conteúdos elencados em um país, que pareiam com a do outro, isto é, não identificamos diferenças nas listas de conteúdos matemáticos.

A tendência do processo de ensino e aprendizagem da Matemática, indicada nos documentos de Brasil, Chile e México, e que é fomentada nas diversas pesquisas em Educação Matemática, é a Resolução de Problemas.

Nos países é reforçada a necessidade de uma formação conceitual, procedimental e atitudinal, mas para isso, dialogam com os conhecimentos, perpassando, no caso do ensino Fundamental, pelos temas transversais e no Ensino Médio por meio de projetos escolares.

$\mathrm{Na}$ Educação chilena e mexicana, há uma ênfase maior em Álgebra, e

\footnotetext{
${ }^{20}$ Pesquisa, que trata este artigo, foi realizada antes da homologação da BNCC (Base Nacional Comum Curricular), vinte de dezembro de dois mil e dezessete
} 
que essa ênfase no Ensino Fundamental está relacionada à prática em detrimento às especulações teóricas.

Já na etapa educacional para alunos com idades compreendidas de 15 a 17 anos, que no Brasil equivale ao Ensino Médio, no Chile a Educação Média e no México a Educação Média Superior, existe quase um equilíbrio, tendendo um pouco mais para as especulações teóricas. Acreditamos que, como essa etapa é a da finalização dos estudos antes ligados ao nível superior, existam uma ponderação entre os conhecimentos para o aluno exercer sua cidadania, assim como apresentá-lo a uma estrutura matemática organizada, estruturada e axiomática. Estamos nos referindo ao rigor da Matemática, para que o aluno compreenda sua cultura.

Revelamos preocupações e orientações com o papel do erro no processo de ensino e aprendizagem da Matemática. Nos países comparados as relações devem ser desenvolvidas no ambiente escolar, entre professores e alunos, alunos e alunos, etc.

Identificamos alguns princípios do construtivismo nos Currículos de Matemática dos países analisados, tais como, o aluno como ser ativo no processo de construção de seu conhecimento; conhecimentos prévios são essenciais ao novo conhecimento ou conteúdo conceitual, etc. Uma característica importante e que difere com o Brasil, é a participação do Centro de Professores e Apoderados (CPA), que é uma organização reconhecida pelo Ministério de Educação chilena e que tem uma presença importante nas escolas, auxiliando os estudantes que apresentam dificuldades de aprendizagem e, ainda, na busca daqueles que fazem parte da evasão escolar, e no caso mexicano está ação não foi identificada em nossas análises comparativas, mas carece de uma análise mais acurada para uma possível identificação. No Brasil, essa ação por parte dos pais e responsáveis pelos alunos não existe, pelo menos oficialmente reconhecido pelo governo brasileiro.

Nos documentos curriculares que elegemos para nossas análises nos países comparados, foram contempladas diversas orientações para o uso dos 
recursos tecnológicos, principalmente calculadoras e computadores. No discurso textual desses documentos é preconizado que as tecnologias estão a serviço da sociedade e por isso, é elementar que os alunos tenham acesso a elas e aprendam a utilizá-las adequadamente, atendendo as necessidades peculiares de cada disciplina.

Outro aspecto marcante e presente nos três países é o da avaliação de aprendizagem dos alunos. Existem diversos instrumentos para esse fim nos dois países. No Brasil, Chile e México, os resultados das avaliações podem oferecer indicativos de possíveis problemas que obstruam os avanços no processo de ensino e aprendizagem da Matemática e, após as análises e reflexão, por parte dos governos de cada país, a partir desses resultados, estabelecer quais rumos tomarem.

Tomada de decisão, que tem a finalidade de reorientar a jornada pedagógica com perspectivas a concretizar as finalidades para o ensino da Matemática. Retomamos a fala de Sacristán (2000) anunciando que o "currículo desde um enfoque processual ou prático e é um objeto que se constrói durante sua configuração, implantação, concretização e expressão de determinadas práticas pedagógicas e em sua própria avaliação, como resultado de diversas intervenções que nele se operam". (SACRISTÁN, 2000, p.101)

Outra diferença que observamos é relacionada com a carga horária anual letiva de cada país. No Chile é de 1680 horas/aula, enquanto que no Brasil e México pode chegar a 1000 horas. No Chile e no Brasil está sendo implantada, muito lentamente, a jornada integral para a Educação Básica nesses países, e no caso mexicano não identificamos possível sistema de ensino e/ou implementação.

Outra diferença entre Brasil e Chile nesse aspecto, é que no Chile existe a possibilidade de gratificação por desempenho escolar durante dois anos. Essa prática, a nosso ver, promove uma disputa acirrada entre as escolas, fomentando, provavelmente, a consecução do currículo prescrito naquele país e melhores aproveitamentos dos estudantes, uma vez que eles são os atores 
que realizam as avaliações que garantirão ou não a gratificação dos professores. No âmbito mexicano não identificamos esse mérito, mas indícios de políticas públicas para implementação de avaliação profissional de professores, esses indícios constatamos em conversar com os professores mexicanos em visita ao México.

No Brasil, alguns estados oferecem um bônus, atrelado a metas, que determinadas secretarias de educação estipulam. Em São Paulo, isso vem acontecendo há alguns anos e é denominado de $14^{\circ}$ (décimo quarto pagamento). Esse décimo quarto pagamento é pago apenas uma vez no início do ano com base no desempenho escolar dos alunos do Ensino Fundamental e Médio mediante um sistema de avaliação denominado SARESP (Sistema de Avaliação do Rendimento Escolar do Estado de São Paulo), sistema que gera um Índice de Desempenho Escolar do Estado de São Paulo, e com base nesse índice calcula-se a bonificação para os professores.

\section{Mudanças Curriculares no Brasil}

Após evidenciarmos algumas semelhanças e diferenças presente nos currículos de Matemática dos três países identificamos várias tendências da Educação Matemática presentes nos currículos oficiais de Chile e México e nos PCNs do Brasil. Nossos estudos em nível de Doutorado em Educação Matemática iniciaram em 2009 e, atualmente, passados 11 anos observamos que no Brasil existe a preocupação em oferecer aos professores um Currículo Oficial de Matemática. O Ministério da Educação apresentou um documento denominado Base Nacional Comum Curricular - BNCC.

Nesse documento é destacado que:

A Base Nacional Comum Curricular (BNCC) é um documento de caráter normativo que define o conjunto orgânico e progressivo de aprendizagens essenciais que todos os alunos devem desenvolver ao longo das etapas e modalidades 
da Educação Básica, de modo a que tenham assegurados seus direitos de aprendizagem e desenvolvimento,em conformidade com o que preceitua o Plano Nacional de Educação (PNE). Este documento normativo aplica-se exclusivamente à educação escolar, tal como a define o $\S 1^{\circ}$ do Artigo $1^{\circ}$ da Lei de Diretrizes e Bases da Educação Nacional (LDB, Lei $n^{\circ}$ 9.394/1996) ${ }^{21}$, e está orientado pelos princípios éticos, políticos e estéticos que visam à formação humana integral e à construção de uma sociedade justa, democrática e inclusiva, como fundamentado nas Diretrizes Curriculares Nacionais da Educação Básica (BRASIL, 2017, p.5)

Nesse sentido entendemos que Base Nacional Comum Curricular (BRASIL, 2017) não é um currículo, mas sim um orientador curricular. A proposta veiculada na BNCC é a de ser um documento balizador da qualidade da Educação, apresentando uma base comum de aprendizagens a todos os estudantes do Brasil e assegurando o desenvolvimento das dez competências gerais, à saber:

1. Conhecimento; 2. Pensamento científico, crítico e criativo; 3. Senso estético; 4. Comunicação; 5. Cultura digital; 6. Argumentação; 7. Autonomia; 8. Empatia e cooperação; 9. Autoconhecimento e autocuidado; 10. Autogestão.

Basicamente todos os estados brasileiros estão envolvidos e já finalizaram seus currículos oficiais de Matemática e atribuíram a cada município a incumbência de elaborarem os currículos considerando as crenças e atividades econômicas regionais, a geografia e as diversidades culturais, etc. Em síntese a intenção presente na $\mathrm{BNCC}$ é a de tornar o estudante o protagonista em todas as situações. A elaboração da BNCC, em 2015, passou

\footnotetext{
${ }^{21}$ BRASIL. Lei ${ }^{\circ}$ 9.394, de 20 de dezembro de 1996. Estabelece as diretrizes e bases da educação nacional. Diário Oficial da União, Brasília, 23 de dezembro de 1996. Disponível em: <http://www.planalto.gov.br/ccivil_03/leis/L9394.htm>. Acesso em: 23 mar. 2017.
} 
por análises de especialistas brasileiros das diversas áreas de conhecimento, sendo apresentada a primeira versão para consulta pública. Em 2016 após analises e considerações foi apresentada em Seminários Estaduais a segunda versão da BNCC e, após a finalização das consultas pública, iniciou-se a sistematização das contribuições.

No ano de 2017 apresentou-se a terceira versão da BNCC. Ocorreram audiências públicas, a aprovação do texto pelo Conselho Nacional de Educação - CNE e o Ministério da Educação e Cultura homologou o documento BNCC.

Nesse cenário, iniciou-se as discussões nas escolas públicas da Educação Básica na perspectiva de os professores apropriarem-se das propostas veiculadas na BNCC e da responsabilidade da sua participação na construção e elaboração dos currículos estaduais e, principalmente, municipais.

Durante o ano de 2018 iniciou-se o período de (re)elaboração dos currículos estaduais e municipais, fomentando consultas públicas sobre as versões reelaboradas e culminando na homologação nos Conselhos de Educação estaduais e municipais.

Temos percorridos diversos municípios colaborando, em projetos de formação com os professores que lecionam no Ensino Fundamental Anos Finais, nas reflexões sobre a reelaboração de currículos municipais e buscando sanar dúvidas pertinentes do processo de transição e implementação dos princípios e objetivos contemplados na BNCC, enfatizando que para o ano de 2020 os currículos deverão ser finalizados.

Além do desafio da reelaboração dos currículos de Matemática, os professores, diretores, supervisores e todos os envolvidos no processo do ensino e aprendizagem deverão rever os Projetos Políticos Pedagógicos - PPC das escolas a partir dos currículos oficiais finalizados.

Na sequência, há de se priorizar, com vistas na superação dos desafios para a implementação da BNCC, a formação continuada de professores, análise e adequação dos livros didáticos, repensar nas avaliações oficiais 
externas e aquelas apresentadas pelos docentes, visando permear o processo continuo de aprendizagem dos estudantes.

Diante do exposto sobre a BNCC implementada após nossa constatação de que no Brasil não havia um currículo oficial de Matemática, identificamos avanços e amadurecimentos pedagógicos por parte dos envolvidos em garantir uma aprendizagem com um núcleo comum para todo o Brasil, uma vez que, na elaboração dos currículos estaduais solicitou-se a integração e o diálogo entre todos os estados da Federação para que, no movimento migratório, o estudante não fosse penalizado com possíveis "perdas" conceituais matemáticos e/ou de outras áreas de conhecimento estudado na Educação Básica.

\section{Nossas considerações}

As políticas educacionais na América Latina têm possibilitado a inserção de crianças e jovens no sistema público de ensino de forma significativa. Mudanças curriculares nos últimos anos da transição do milênio têm provocada discussões que afloram numa busca de atender necessidades locais - no que tange aos aspectos social, emocional e profissional - elevar os índices de qualidade dos sistemas educacionais e capacitar profissionais da educação para estarem alinhados as novas mudanças curriculares.

Essas mudanças curriculares são frutos dos anseios por parte da sociedade para o atendimento de demandas, portanto, essas mudanças é uma construção social com participação de cidadãos, assim como aconteceu nos Estados Unidos em meados do século passado em que a construção do currículo teve a participação da sociedade.

Outro aspecto importante nessas mudanças é o desenvolvimento de competências que vem permeando desde as últimas mudanças curriculares. Esse desenvolvimento tem orientado as construções de vários currículos de municípios, estados e países. O desenvolvimento de competências também está focado nas avaliações dos currículos, inclusive nas internacionais, com 
no Programa Internacional de Avaliação de Alunos - PISA - sigla em inglês.

No patamar de trabalhar com estudos comparativos, não só no entendimento de identificar similaridades e diferenças, esses estudos propõem buscar pontos fracos e fortes para implementação de melhorias no sistema educativo sem devastar os costumes locais de determinado povo ou nação. O que permeia ao estudo comparativo dos países pesquisas sobre a Educação Matemática, a nossa assertiva é que sua influência está presente nos Currículos Prescritos de Matemática, e que os elaboradores e/ou implementadores de Currículos de Matemática atuam como pesquisadores na Educação Matemática.

Portanto, os estudos comparativos dos países explanados neste texto visam uma ampliação de como os Currículos de Matemática estão sendo desenvolvidos e implementados, e quais caminhos na atual conjuntura serão trilhados para que Currículos de Matemática atendem demandas da sociedade cada vez mais complexas.

\section{Referências}

ALARCÃO, I. Reflexão crítica sobre o pensamento de D. Schön e os programas de formação de professores. In: Revista da Faculdade de Educação, n. ${ }^{\circ}$ 22, Jul/Dez, São Paulo. 1996.

BRASIL. Lei n ${ }^{\circ}$ 9.394, de 20 de dezembro de 1996. Estabelece as diretrizes e bases da educação nacional. Diário Oficial da União, Brasília, 23 de dezembro de 1996. Disponível em: <http://www.planalto.gov.br/ccivil_03/leis/L9394.htm>. Acesso em: 23 mar. 2017.

BRASIL. Ministério da Educação (MEC). Parâmetros Curriculares Nacionais Matemática terceiro e quarto ciclos do Ensino Fundamental, 1998.

BRASIL. Ministério da Educação (MEC). Secretaria do Ensino Fundamental. Parâmetros Curriculares Nacionais. Matemática. $1^{\circ}$ e $2^{\circ}$ ciclos. 1997.

BRASIL. Ministério da Educação; Secretaria de Educação Básica. Base Nacional Comum Curricular. Brasília, DF, 2017, MEC; SEB; DICEI, 2013. Disponível em: http://portal.mec.gov.br/index.php?option $=$ com docman\&view $=$ download\&alias $=79$ 601-anexo-texto-bncc-reexportado-pdf-2\&category slug=dezembro-2017pdf\&Itemid=30192. Acesso em: 16 out. 2019.

BRASIL. Parâmetros Curriculares Nacionais - Matemática Ensino Médio, bases 
legais, Brasília, 1999.

BRASIL. Parâmetros Curriculares Nacionais - Matemática Ensino Médio - PCN+. Orientações Educacionais Complementares aos Parâmetros Curriculares Nacionais, 2002.

CERQUERIA, D. S. Um estudo comparativo entre Brasil e Chile sobre a Educação Matemática e sua influência nos Currículos de Matemática desses países. Tese de Doutorado. Programa de Estudos Pós-graduados em Educação Matemática da Pontifícia Universidade Católica de São Paulo, PUC/SP, 2012.

CHILE. Guia Ayuda Mineduc. Educación Básica - 2010 - MINEDUC.

CHILE. Ministerio de Educación de Chile. LEY N 20.370 - Ley de Educación Nacional. Chlile, 12 - SEP-2009.

CHILE. Objetivos Fundamentales y Contenidos Mínimos Obligatorios de La Educación Media - MINEDUC.

FERRER, F. J. La Educación comparada actual. Barcelona, Ed. Ariel, 2002.

LÜDKE, M.; ANDRÉ, M. E. D. A. Pesquisa em educação: abordagens qualitativas. São Paulo: EPU, 1986.

MÉXICO. Documento base del bachillerato general. Subsecretaria de Educación Media Superior. Dirección General del Bachillerato. Ciudad de México, Secretaría de Educación Pública, 2011.

MÉXICO. La Estructura del Sistema Educativo Mexicano. Disponível em: www.sep.gob.mx/work/models/sep1/.../sistemaedumex09_01.pdf. Acesso em: 30 de julho de 2013.

MÉXICO. Programa de Estudio 2011- Guía para la educadora - Educación Básica Preescolar. Cidade do México. SEP - Secretaría de Educación Pública. 2011.

PIRES, C. M. C. Currículos de Matemática: da organização linear à idéia de rede. São Paulo, FTD, 2000.

SACRISTÁN, J. G. O Currículo: uma reflexão sobre a prática. Porto Alegre: ArtMed, 2000.

SILVA, M.N. A Educação Matemática na América Latina: um estudo comparativo dos Currículos de Matemática do Brasil e México. Tese de Doutorado. Programa de Estudos Pós-graduados em Educação Matemática da Pontifícia Universidade Católica de São Paulo, PUC/SP, 2017. 